Hydraulic Engineering Repository

Ein Service der Bundesanstalt für Wasserbau

Gebhardt, Michael; Pfrommer, Udo; Belzner, Fabian; Eisenhauer, Norbert Backwater effects of Jambor weir sill

Verfügbar unter / Available at:

https://hdl.handle.net/20.500.11970/104558

Vorgeschlagene Zitierweise / Suggested citation:

Gebhardt, Michael; Pfrommer, Udo; Belzner, Fabian; Eisenhauer, Norbert (2012): Backwater effects of Jambor weir sill. In: Journal of Hydraulic Research (IAHR) 50 (3). S. 344-349. 
Erstveröffentlichung in Journal of Hydraulic Research 3 (2012), S. 344-349.

Für eine korrekte Zitierbarkeit ist die Seitennummerierung der Originalveröffentlichung für jede Seite kenntlich gemacht.

\title{
Backwater effects of Jambor weir sill
}

\author{
Michael Gebhardta, Udo Pfrommerb, Fabian Belznerc, Norbert Eisenhauerd \\ a Dr.-Ing., Research Engineer, Department of Hydraulic Engineering in Inland Areas, Federal Waterways Engineering and \\ Research Institute, Kussmaulstr. 17, D-76187 Karlsruhe, Germany. Email: michael.gebhardt@baw.de (author for corre- \\ spondence) \\ b Dipl.-Ing. (FH), Research Engineer, Department of Hydraulic Engineering in Inland Areas, Federal Waterways Engineer- \\ ing and Research Institute, Kussmaulstr. 17, D-76187 Karlsruhe, Germany. Email: udo.pfrommer@baw.de \\ c M. Eng., Research Engineer, Department of Hydraulic Engineering in Inland Areas, Federal Waterways Engineering and \\ Research Institute, Kussmaulstr. 17, D-76187 Karlsruhe, Germany. Email: fabian.belzner@baw.de \\ d Professor, Hydraulic Research Laboratory, University of Applied Sciences, Moltkestraße 30, D-76133 Karlsruhe, Germa- \\ ny. Email: norbert.eisenhauer@hs-karlsruhe.de
}

Revision received 17 April 2012/Open for discussion until 30 November 2012.

Compared with traditional weirs, Jambor weirs have the advantage that they reduce afflux due to their hydraulically-optimized shape. Hence, for identical discharge capacity, the height of the gate and thus the cost are reduced significantly. Although Jambor weir sills have been used in a combination with movable weirs for decades, the relationship between sill height, headwater and tailwater conditions and the resulting discharge has so far not been investigated systematically. Based on extensive tests in a hydraulic flume, an empirical equation and a dimensionless design chart were developed to estimate the backwater effect in the design phase to achieve the highest possible weir sill with an optimum hydraulic performance.

Keywords: Backwater effect; broad-crested weir; drag coefficient; submerged flow; weir sill

\section{Introduction}

A weir consists of a concrete weir sill and one or more movable gates regulating the upstream water level for navigation or hydropower purposes. Under design, discharge occurs often in submerged flow conditions, so that a flood-neutral design is relevant. Many papersdeal with discharge coefficients for free flow and the transition to submerged flow at standard weirs, yet less information is dedicated to the water level rise due to the weir sill under the described conditions. In contrast to free flow, the weir sill causes an energy loss due to flow contraction. Jambor (1953, 1959) found that with an appropriate design, the height of the weir sill can reach $25-30 \%$ of the upstream flow depth without a "noticeable" backwater effect. The height of a movable gate and thus the cost are significantly reduced, while the weir discharge capacity is maintained. The Jambor weir sill has been realized in the past at German waterways with various gate types, including sector gates, flap gates, tainter gates or inflatable dams, but also as a ground sill (Fig. 1). 


\section{Autorenfassung}

Gebhardt, Pfrommer, Belzner, Eisenhauer: Backwater effects of Jambor weir sill, 2012

The investigations of Jambor $(1953,1959)$ are considered of practical interest, but they are published only in German. The purpose of this note is to update the available information, because no general statements are available yet, allowing for its design including the discharge determination under various hydraulic conditions. General recommendations for the weir shape can be found in Blind (1987). Furthermore, requirements concerning the flood-neutrality of newly built or restored weirs have changed over the years, so that from today's perspective the "noticeable" backwater effect may be seen in a different way and, in most cases, a quantitative statement is expected. Systematic model studies form the basis for a generally applicable method allowing for estimating the height of a Jambor weir. The focus of this study is on

Gebhardt, Pfrommer, Belzner, Eisenhauer:

Backwater effects of Jambor weir sill

Journal of Hydraulic Research (2012), S. 344-349.

(a)

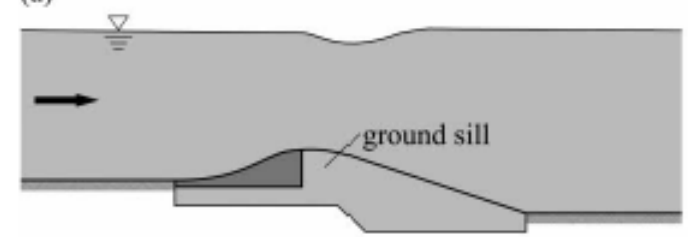

(b)

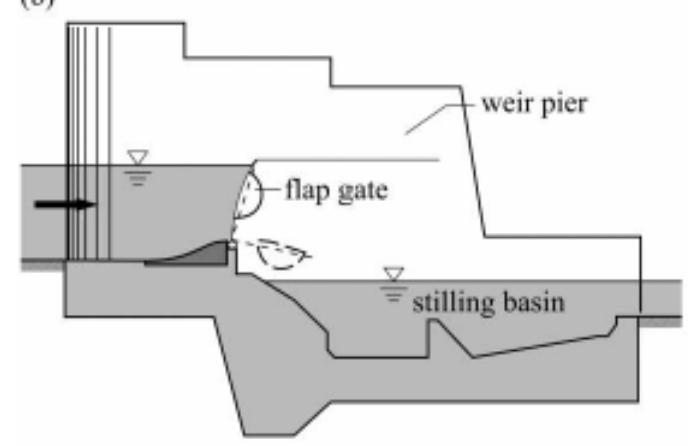

(c)

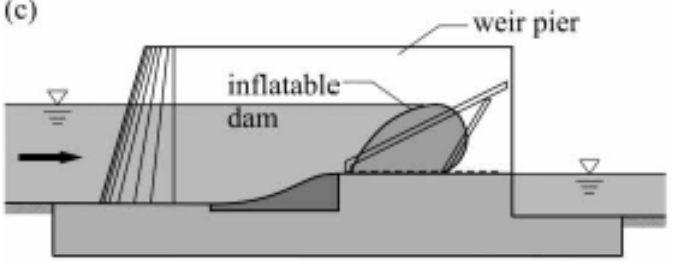

(d)

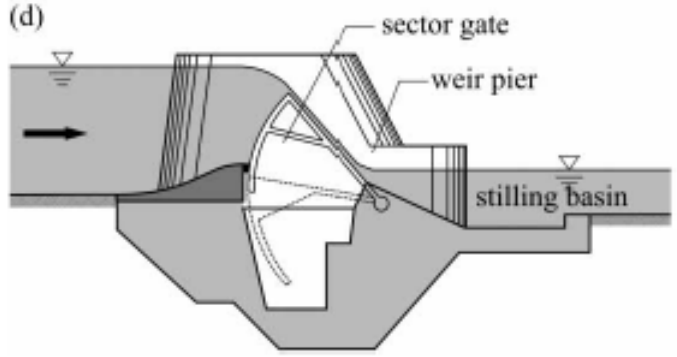


Figure 1 Examples of Jambor weir sills with a (a) ground sill, (b) flap gate, (c) inflatable dam, (d) sector gate

the Jambor weir in conjunction with an inflatable dam, because of the increasing interest for that weir type (Gebhardt 2010). As shown below, the results apply also to other types of gates.

\section{Theoretical background}

\subsection{Flow features above weir sill}

Although a weir sill is part of a (combined) weir, the term control structure is somewhat misleading in this context, because for design discharge the flow above the sill may not be at the critical state. This requires a high tailwater level $\mathrm{y}_{2}$ and submerged flow for the design discharge. To determine the application limits, the maximum height of a weir sill is determined using the Bernoulli equation by neglecting frictional forces and energy dissipation over the sill (Chadwick and Morfett 1998). Using the continuity equation and introducing the tailwater Froude number $\mathrm{F}_{2}$ leads to

$$
\frac{w_{\max }}{y_{2}} \leq 1+\frac{\mathrm{F}_{2}^{2}}{2}-\frac{3}{2} \cdot \sqrt[3]{\mathrm{F}_{2}^{2}}
$$

At the maximum sill height $\mathrm{w}_{\max }$, the critical depth $\mathrm{y}_{\mathrm{c}}$ is reached, so that the headwater level is independent of the tailwater and, subsequently a function of only the approach flow Froude number $\mathrm{F}_{1}$. Equation (1) is, thus, the application limit for the Jambor weir. Above this limit, the overflow corresponds to that of a broad-crested weir with parallel streamlines, as analysed by Hager and Schwalt (1994) for free, undular and submerged flow. Ramamurthy et al. (1988) and Heimann (2009) studied the discharge characteristics of round-and square-crested weirs, which are related applications to the Jambor weir regarding the coefficient of discharge. Gonzales and Chanson (2007) performed velocity and pressure measurements in a nearly full-scale broadcrested weir. Further related applications include long-throated flumes and Venturi flumes. These all have a streamlined converging transition that leads to a raised sill and/or narrowed throat section within which critical-depth flow occurs. Typical designs are presented by Bos et al. (1984) or Wahl et al. (2005).

\subsection{Design criteria}

Jambor $(1953,1959)$ used the effect of flow acceleration above a convex-curved bottom based on Lauffer (1936) or recently by Bagheri and Heidarpour (2010). Lauffer (1936) deriving the pressure and velocity distributions indicated that in addition to the inertia and gravitational force, the centrifugal force acts on a fluid particle resulting in a pressure reduction. According to Bernoulli's equation, this pressure reduction is converted into a velocity increase. Jambor $(1953,1959)$ found an optimum curvature radius of the upstream bend using hydraulic modelling. To prevent sediment 
deposition, the design includes an oppositely curved transition portion resulting in an S-shaped ramp, with the transition radii varying with the sill height (Fig. 2).

\section{Model investigations}

\subsection{Experimentation}

For hydraulic structures such as spillways or weirs with rapidly changing free surface profiles, the two predominant forces are inertia and gravity. Therefore, the Froude numbers of the model and the prototype have to be identical. Additionally, the flow should be turbulent to obtain similar conditions concerning separation and boundary layer effects at the sill top. The model Reynolds numbers $R=\left(v \cdot R_{h}\right) / v$ were between 6000 and 120,000, i.e. high enough for fully-turbulent flow conditions, so that viscous effects are negligible (Henderson 1966, Heller 2011).

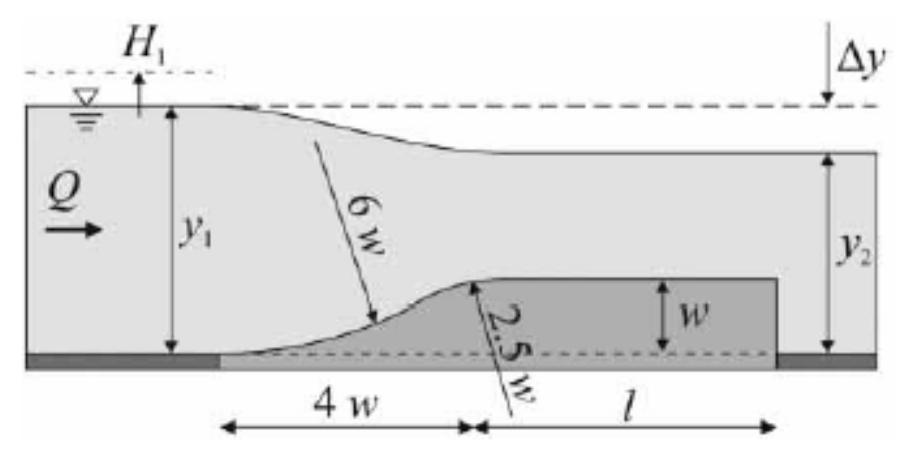

Figure 2 Flow above Jambor weir, definition sketch

Gebhardt, Pfrommer, Belzner, Eisenhauer:

Backwater effects of Jambor weir sill Journal of Hydraulic Research (2012), S. 344-349.

The weir discharge is described in terms of the difference in the up- and downstream water levels $\Delta \mathrm{y}=\mathrm{y}_{1}-\mathrm{y}_{2}$ (Fig. 2). Based on a dimensional analysis,

$$
\frac{\Delta y}{y_{2}}=f\left(\mathrm{~F}_{2}, \frac{y_{2}}{w}\right)
$$

Since the shape of the Jambor weir sill varies with the sill height $w$, the two radii are not independent of each other. The effect of the broad-crested weir length on the discharge is discussed in Section 4.2 . 


\subsection{Measurement techniques}

The tests were conducted in a rectangular horizontal channel $15 \mathrm{~m}$ long, $2.33 \mathrm{~m}$ wide and $0.57 \mathrm{~m}$ high. The channel was supplied by a constant head tank of $350 \mathrm{l} / \mathrm{s}$ maximum discharge. The discharge was measured using a magnetic-inductive flow meter ABB MAG-XM with $\pm 0.8 \mathrm{l} / \mathrm{s}$ accuracy, whereas the tailwater level was set with a digitally-controlled flap gate. Six measurement points were placed throughout the channel at intervals of 1.25-2 m. The flow depths were measured with self-developed ultrasonic probes in lateral tubes according to the principle of communicating vessels, of $\pm 0.1 \mathrm{~mm}$ reading accuracy. The measurement point for the tailwater level was set 5.85 mdownstream of the Jambor weir, where neither the weir (hydraulic jump or waves) nor the flap gate (drawdown or backwater curve, flow profile) has any influence. The upstream water level was measured approximately $2.60 \mathrm{~m}$ upstream from the sill.

\subsection{Test program}

Five weir sill heights between $\mathrm{w}=2.9$ and $14.3 \mathrm{~cm}$ were examined. For each, 7 tailwater levels between $\mathrm{y}_{2}=5.7$ and $40.0 \mathrm{~cm}$ and 16 discharges between $\mathrm{Q}=19.5$ and $312.2 \mathrm{l} / \mathrm{s}$ were considered resulting in 112 runs per sill, i.e. a total of 560 runs. Additionally, reference measurements were made without a weir sill to determine the channel roughness, using a combination of 7 tailwater levels and 16 discharges. In a preliminary test regarding the effect of different sill lengths, further runs were conducted with three different lengths $(0,59$ and $118 \mathrm{~cm})$ for, e.g. $w=14.3 \mathrm{~cm}$.

\subsection{Backwater effect}

The observations suggest that the backwater effect $\Delta y / y_{2}$ varies with $F_{2}$ and the relative sill height $\mathrm{y}_{2} / \mathrm{w}$. To correlate the data, first the friction loss was eliminated by subtracting the water level difference due to frictional loss obtained from the reference measurements. The next step was to develop a semi-empirical function. In ideal-fluid flow, for hydrostatic pressure and uniform velocity distributions, the Bernoulli equation applies between the cross sections up- and downstream of the sill. By introducing $F_{2}=v_{2} /\left(g \cdot y_{2}\right)^{1 / 2}$ and the continuity equation the backwater effect is

$$
\frac{\Delta y}{y_{2}}=\frac{\mathrm{F}_{2}^{2}}{2}-\frac{\mathrm{F}_{2}^{2}}{2}\left(\frac{y_{2}}{y_{1}}\right)^{2}+\frac{\Delta H}{y_{2}}
$$

Here, $\Delta \mathrm{H}$ is the energy loss described as the product of a loss coefficient $\zeta$ and the velocity head of the upstream flow, so that

$$
\frac{\Delta y}{y_{2}}=\frac{\mathrm{F}_{2}^{2}}{2} \cdot\left(1-\left(\frac{y_{2}}{y_{1}}\right)^{2}+\zeta \cdot\left(\frac{y_{2}}{y_{1}}\right)^{2}\right)
$$

Coefficient $\zeta$ can be expressed by the product of a drag coefficient $c_{w}$ and the ratio of sill height and tailwater level like it is shown for the drag of a bridge pier (Naudascher 1991) or for channel constriction (Chow 1973) as 


$$
\zeta=c_{w} \cdot \frac{w}{y_{2}}
$$

Substituting Eq. (5) into Eq. (4) leads to

$$
\frac{\Delta y}{y_{2}}=\frac{\mathrm{F}_{2}^{2}}{2} \cdot\left(1-\left(\frac{y_{2}}{y_{1}}\right)^{2}+c_{w} \cdot \frac{w}{y_{2}} \cdot\left(\frac{y_{2}}{y_{1}}\right)^{2}\right)
$$

To obtain a more convenient form, the following simplification can be adopted. Since a low backwater effect should be reached, the ratio $\mathrm{y}_{2} / \mathrm{y}_{1} \rightarrow 1$, so that

$$
\left(\frac{y_{2}}{y_{1}}\right)^{2} \approx 1
$$

Thus, Eq. (6) simplifies to

$$
\frac{\Delta y}{y_{2}}=c_{w} \cdot \frac{w}{y_{2}} \cdot \frac{\mathrm{F}_{2}^{2}}{2}
$$

The drag coefficient $c_{w}$ was obtained by fitting Eq. (8) with the least-squares method.

\section{Experimental results}

\subsection{Variation of $C_{d}$ for free flow}

Figure 3 shows the variation of the discharge coefficient $\mathrm{C}_{\mathrm{d}}$ with the relative crest length $\xi=\left(\mathrm{H}_{1}-\right.$ $w) /\left(H_{1}-w+l\right)$ for free flow (i.e. $\left.y_{2} / y_{1}<0.85\right)$. For comparison purposes, the equations $C_{d}(\xi)$ for embankment (Fritz and Hager 1998) and broad-crested weirs (Hager and Schwalt 1994) are also plotted. The present data show an increasing $C_{d}$ value with increasing $\xi$, although the data scatter. The minimum value $C_{d}(\xi<0.08)$ is slightly lower than the basic value 0.326 for broad-crested weirs due to scale effects $\left(\mathrm{H}_{1}<50 \mathrm{~mm}\right)$. Overall, the results of this study agree well with those of Fritz and Hager (1998). Figure 3 also shows the lower discharge capacity of standard broad-crested weirs due to the larger separation zone at the upstream corner.

Gebhardt, Pfrommer, Belzner, Eisenhauer:

Backwater effects of Jambor weir sill

Journal of Hydraulic Research (2012), S. 344-349. 


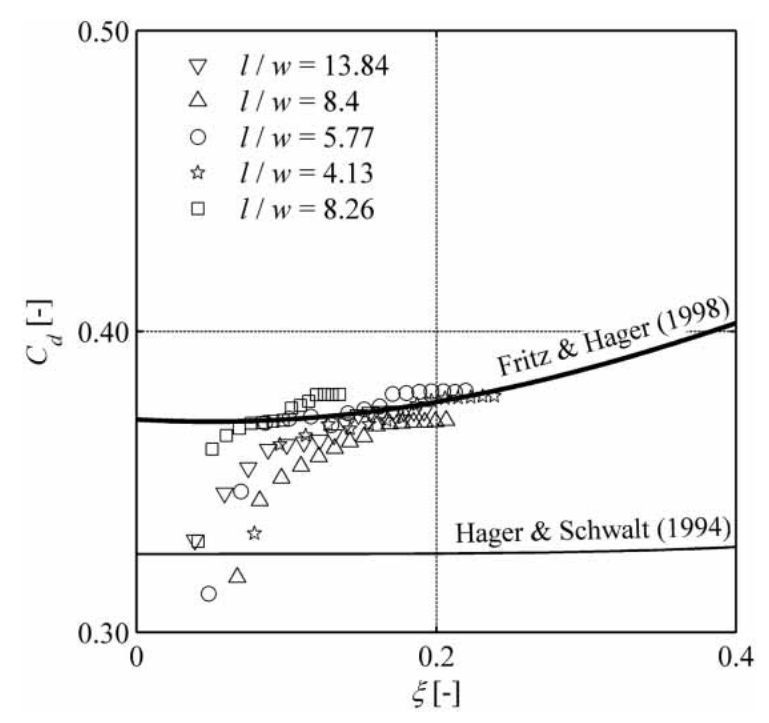

Figure 3 Discharge coefficient $C_{d}$ of Jambor weir sill versus relative weir length $\xi$. Comparison with embankment weirs (Fritz and Hager 1998) and broad-crested weirs (Hager and Schwalt 1994)

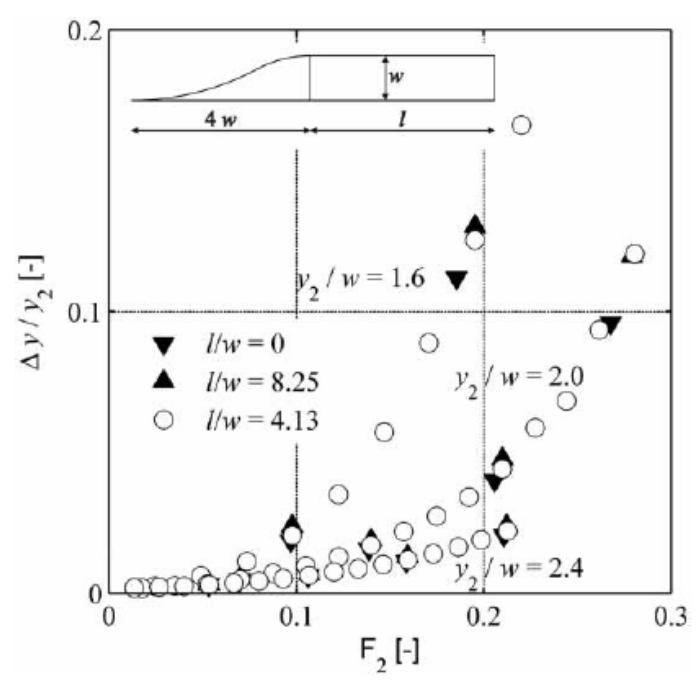

Figure 4 Effect of crest length on afflux $\Delta y / y_{2}$ versus Froude number $F_{2}$

\subsection{Effect of sill length and deflated membrane}

A deflated rubber membrane requires a length of the weir body corresponding to at least 2.3 times the design dam height of a water-filled type (Japanese Institute of Irrigation and Drainage 1989). The length $l$ of the weir crest thus decreases with increasing $\mathrm{w}$, where the top water level $\mathrm{y}_{1}$ is assumed to be constant, e.g. at a given concession water level. Hence, $\mathrm{l}=2.3\left(\mathrm{y}_{2, \max }-\mathrm{w}\right)$, where $\mathrm{y}_{2, \max }=$ $40 \mathrm{~cm}$ is the maximum downstream test flow depth. To study the influence of the overall length, a 


\section{Autorenfassung}

Gebhardt, Pfrommer, Belzner, Eisenhauer: Backwater effects of Jambor weir sill, 2012

test series was performed with $\mathrm{w}=14.3 \mathrm{~cm}$ without subsequent horizontal weir crest and with crest lengths of $\mathrm{l}=59 \mathrm{~cm}$ and $\mathrm{l}=118 \mathrm{~cm}$.

Figure 4 shows the test data for three sills versus $F_{2}$, where the length of the weir crest has no influence. Thus, the surface resistance caused by wall shear stress compared with the form drag caused by the change in pressure distribution is negligible. The sill height and its geometry remain the only relevant factors. Therefore, the examined afflux applies not only for Jambor weirs in connection with inflatable dams, but also for other gate types, provided submerged flow is involved.

\subsection{Backwater effect}

The performance limit of flow measurement devices in Section 2.1 is the modular limit, which separates free and submerged flow. Wahl (2002) estimated for a long-throated flume of constant width a modular limit of 0.85. According to Hager and Schwalt (1994), the modular limit for a broadcrested weir is always above 0.70 , typically at 0.75 . Fritz and Hager (1998) found for embankment weirs a modular limit as a function of the relative crest length $\xi$. For very long-crested weirs, the upper value is 0.85 . Herein, a modular limit of the Jambor weir was not determined, but the submergence ratio $y_{2} / y_{1}$ was achieved to be well above the modular limit. The submergence ratio was in a range between 0.917 and 0.990 . The median was 0.988 , so that the test data are located clearly above the modular limit for related applications. Undular and non-undular hydraulic jumps at
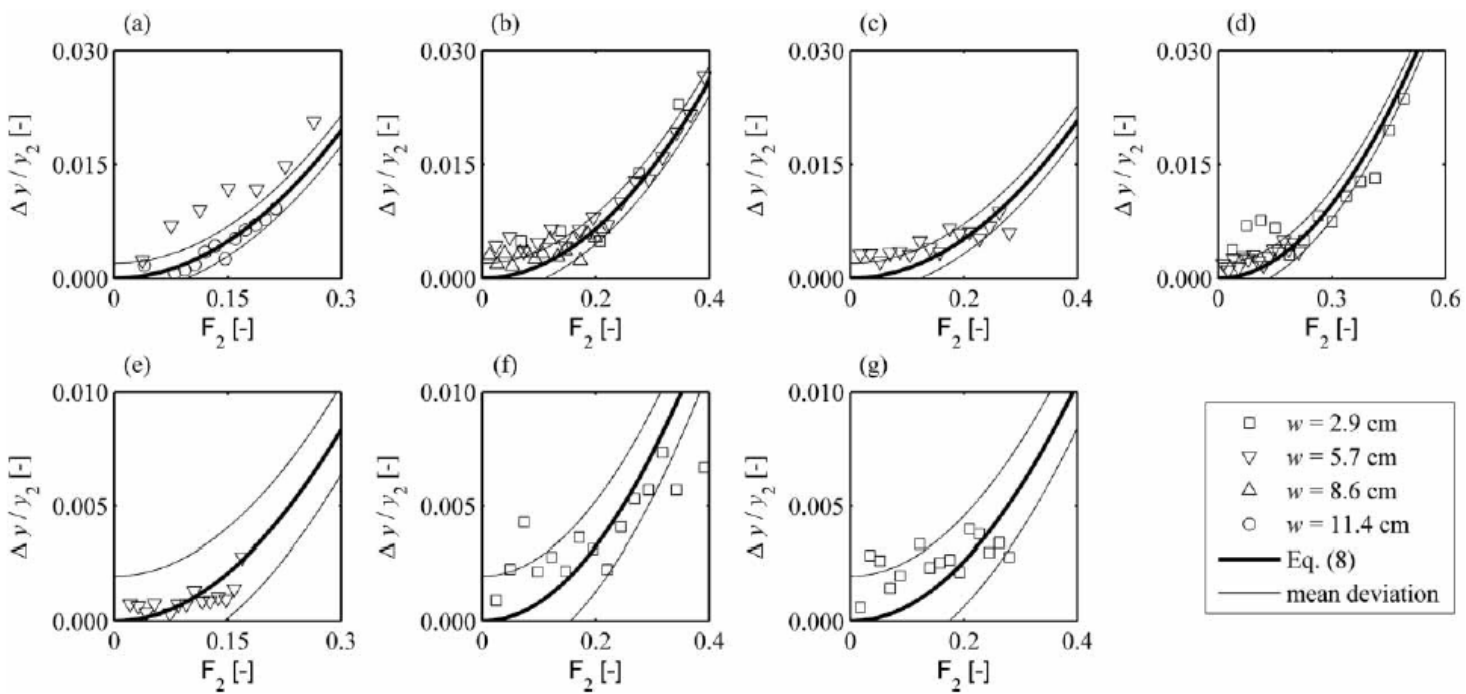

Figure 5 Comparison of measured and calculated $\Delta y_{1} / y_{2}$ using Eq. (8) for $y_{2} / w=$ (a) 3, (b) 4, (c) 5, (d) 6, (e) 7, (f) 8, (g) 10 
Gebhardt, Pfrommer, Belzner, Eisenhauer:

Backwater effects of Jambor weir sill

Journal of Hydraulic Research (2012), S. 344-349.

the weir sill upto slight wave action were observed, as described also by Hager and Schwalt (1994). Figure 5 shows the variation of $\Delta y_{1} y_{2}$ with $F_{2}$ and $y_{2} / w$ computed with Eq. (8) against the test data for ratios $\mathrm{y}_{2} / \mathrm{w}$ between 3 and 10 . Note that further non-integer ratios up to 1.33 exist which are not displayed in Fig. 5, i.e. the data for $\mathrm{w}=14.3 \mathrm{~cm}$.

The experimental dataindicate an increase of $\Delta y_{/} / y_{2}$ with increasing $F_{2}$. The solid line relates to the fitted curve based on Eq. (8). The best approximation resulted for $c_{w}=1.30$, indicating that the quadratic relation actually exists. The scatter of data around the computed line is \pm 0.002 , corresponding to the mean deviation. The data show some large scatter for $\mathrm{y}_{2} / \mathrm{w}=3$, where the $\Delta \mathrm{y}_{2} \mathrm{y}_{2}$ for $\mathrm{w}=5.7 \mathrm{~cm}$ is slightly larger than forw $=11.4 \mathrm{~cm}$. These differences are believed to be caused by different test conditions, i.e. the temperature effect on ultrasonic probes in lateral tubes or differences in calibration. Furthermore, the data also suggest that a small afflux remains for $\mathrm{F} 2 \rightarrow 0$, i.e. for $\mathrm{y}_{2} / \mathrm{w}=4$, so that the curve was fitted through the origin. Overall, the comparison between the measured and calculated values is considered fair. Hence, Eq. (8) is an appropriate approach for estimating the backwater effect.

\subsection{Design chart}

The use of design charts in hydraulic and structural engineering is quite common and useful as a quick and accurate, easy-to-follow reference. Hence, a chart was developed based on Eq. (8) for dimensionless sill heights $\mathrm{y}_{2} / \mathrm{w}$ and $\mathrm{F}_{2}$ (Fig. 6). In addition, the application limit for the Jambor weir is shown based on Eq. (1).

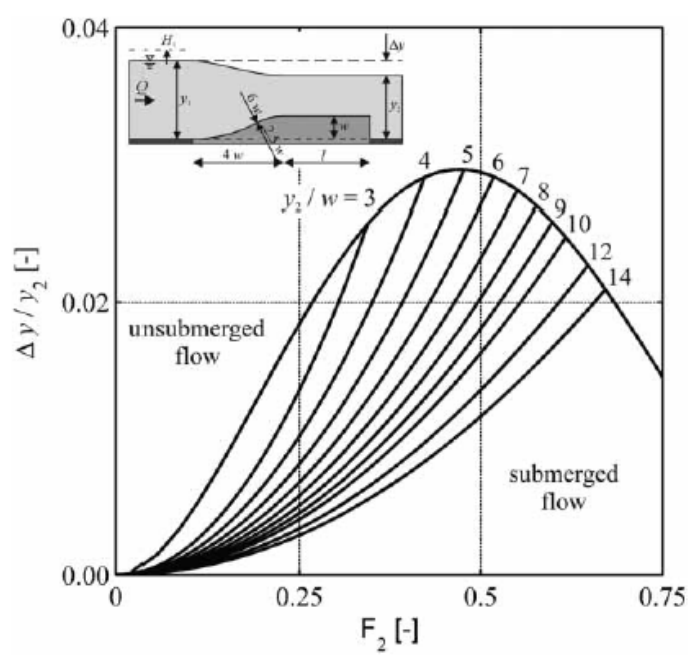


Figure 6 Design chart to estimate afflux $\Delta y_{/} / y_{2}$ versus dimensionless sill height $y_{2} / w$ and Froude number $\mathrm{F}_{2}$

\section{Conclusions}

The overflow of a Jambor weir for a wide range of design parameters is systematically investigated. The focus was on submerged flow which is often relevant for movable weirs. The study indicates a rapid increase of the discharge if the flow above the sill is at the critical state. For free flow, the resulting discharge coefficient is in good agreement with those of embankment and broad-crested weirs. Furthermore, comparative results indicate that the length of the weir crest has no effect and the sill height remains the relevant factor. Within the investigated flow conditions, a high submergence ratio was achieved to be well above the modular limit. From the data, a generalized equation and a dimensionless design chart were developed, allowing for the estimation of the backwater effect as a function of the tailwater Froude number and the relative sill height. According to the authors' experience, it is somewhat surprising that the Jambor weir sill is currently not particularly well-known, despite the fact that its advantage that the height, and thus the cost of a movable gate can be significantly reduced while maintaining the weir discharge capacity.

\section{Notation}

$\begin{array}{lll}\mathrm{b} & = & \text { channel width }(\mathrm{m}) \\ \mathrm{C}_{\mathrm{d}} & = & \text { discharge coefficient }=\mathrm{Q} / \mathrm{b}\left(2 \mathrm{gH}_{1}^{3}\right)^{0.5}(-) \\ \mathrm{C}_{\mathrm{w}} & = & \text { drag coefficient }(-) \\ \mathrm{F} & = & \text { Froude number }=\mathrm{v} /(\mathrm{gy})^{0.5}(-) \\ \mathrm{g} & = & \text { gravitational acceleration }\left(\mathrm{m} / \mathrm{s}^{2}\right) \\ \mathrm{H} & = & \text { energy head }(\mathrm{m}) \\ \mathrm{l} & = & \text { crest length }(\mathrm{m}) \\ \mathrm{Q} & = & \text { discharge (m } 3 / \mathrm{s}) \\ \mathrm{R} & = & \text { Reynolds number }=(\mathrm{vR}) / \mathrm{v}(-) \\ \mathrm{R}_{\mathrm{h}} & = & \text { hydraulic radius }=(\mathrm{by}) /(\mathrm{b}+2 \mathrm{y})(\mathrm{m}) \\ \mathrm{v} & = & \text { velocity }(\mathrm{m} / \mathrm{s})\end{array}$




\section{Autorenfassung}

Gebhardt, Pfrommer, Belzner, Eisenhauer: Backwater effects of Jambor weir sill, 2012

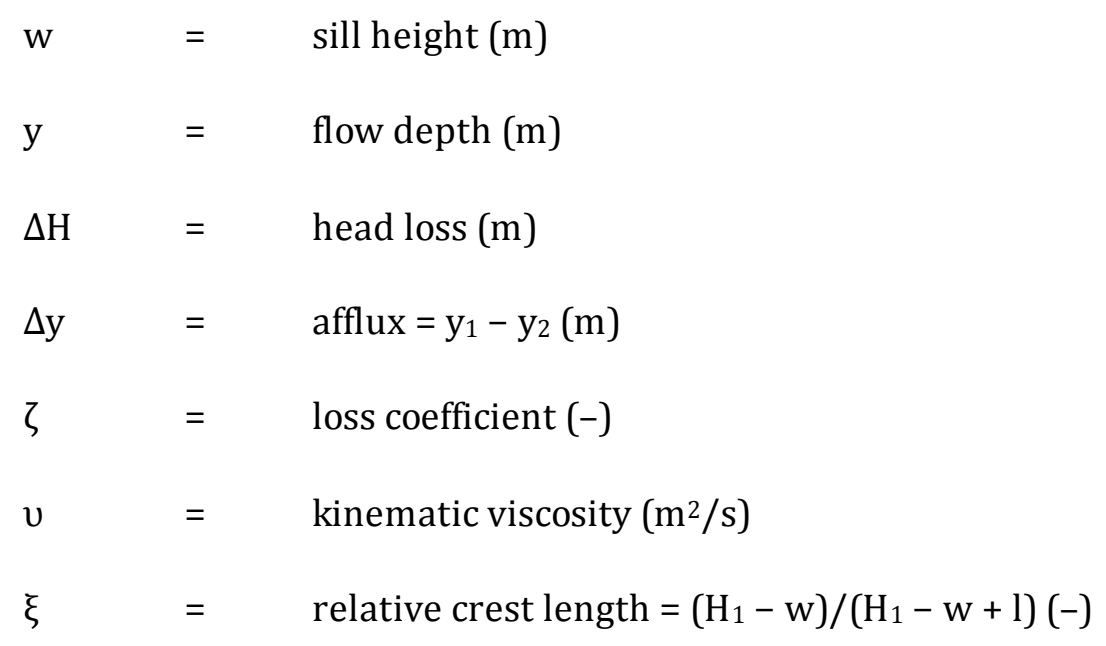

\section{Subscripts}

$\begin{array}{lll}1 & = & \text { upstream } \\ 2 & = & \text { downstream } \\ \mathrm{c} & = & \text { critical flow } \\ \max & = & \text { maximum }\end{array}$

\section{References}

Bagheri, S., Heidarpour, M. (2010). Overflow characteristics of circular-crested weirs. J.Hydraulic Res. 48(4), 515-520.

Blind, H. (1987).Wasserbauten aus Beton (Hydraulic structures of concrete). Ernst \& Sohn, Berlin (in German).

Bos, M.G., Replogle J.A., Clemmens, A.J. (1984). Flow measuring flumes for open channel systems. Wiley, New York.

Chadwick, A.J., Morfett, J.C. (1998). Hydraulics in civil and environmental engineering, 3rd ed. Spon, London.

Chow, V.T. (1973). Open-channel hydraulics. McGraw-Hill, Singapore.

Fritz, H.M., Hager, W.H. (1998). Hydraulics of embankment weirs. J. Hydraulic Eng. 124(9), 963971. 
Gebhardt, Pfrommer, Belzner, Eisenhauer:

Backwater effects of Jambor weir sill

Journal of Hydraulic Research (2012), S. 344-349.

Gebhardt, M. (2010). On the causes of vibrations and the effects of countermeasures at water-filled inflatable dams. Proc. 1st European IAHR Congress Edinburgh (CD-Rom).

Gonzales, C.A., Chanson, H. (2007). Experimental measurements of velocity and pressure distributions on a large broad-crested weir. Flow Meas. Instrument. 18(3-4), 107-113.

Hager, W.H., Schwalt, M. (1994). Broad-crested weir. J. Irr. Drainage Eng. 120(1), 13-26.

Heimann, S. (2009). Betrachtungen zum Abfluss über ein breitkroniges Wehr (Investigations on discharge above a broadcrested weir). Wasserwirtschaft 99(12), 28-31 (in German).

Heller, V. (2011). Scale effects in physical hydraulic engineering models. J.Hydraulic Res. 49(3), 293-306.

Henderson, F.M. (1966). Open channel flow. Macmillan, New York.

Jambor, F. (1953). Erhöhung der festen Wehrschwelle bei gleicher hydraulischer Leistung (Increase of fixed weir sill at identical hydraulic capacity). Mitteilungsblatt der Bundesanstalt für Wasserbau 1, 1-2 (in German).

Jambor, F. (1959). Mögliche Erhöhung der festenWehrschwelle sowie Gestaltung der damit verbundenen Wehrkonstruktion, im Besonderen des Sektorwehrs (Possible increase of fixed weir-sill and arrangement of the associated weir design, especially the sector gate). Die Bautechnik 36(6), 221-228; 36(8), 297-300 (in German).

Lauffer, H. (1936). Strömung in Kanälen mit gekrümmter Sohle (Flow in channels with curved bottom). Wasserkraft und Wasserwirtschaft 31(19), 245-249; 31(20), 260-264 (in German).

Naudascher, E. (1991). Hydrodynamic forces. IAHR Hydraulic Structures Design Manuals 3. Balkema, Rotterdam.

Ramamurthy, A.S., Tim, U.S., Rao, M.V.J. (1988). Characteristics of square-edged round-nosed broadcrested weirs. J. Irr. Drainage Eng. 114(1), 61-73. 


\section{Autorenfassung}

Gebhardt, Pfrommer, Belzner, Eisenhauer: Backwater effects of Jambor weir sill, 2012

The Japanese Institute of Irrigation and Drainage (1989). Engineering manual for irrigation \& drainage, inflatable rubber dams, 444-464. Tokyo, Japan.

Wahl, T.L. (2002). Performance limits of width-contracted flumes. Proc. EWRI/IAHR Conf. Hydraulic measurements and experimental methods Estes Park CO, 1-7.

Wahl, T.L., Clemmens, A.J., Replogle, J.A., Bos, M.G. (2005). Simplified design of flumes and weirs. J. Irr. and Drainage ICID 54(2), 231-247. 